Case Report

\title{
Persistent Hypercalcemia and Hyperparathyroidism in a Horse
}

\author{
Claudia Cruz Villagrán, ${ }^{1}$ Nicholas Frank, ${ }^{1}$ James Schumacher, ${ }^{1}$ and Danielle Reel ${ }^{2}$ \\ ${ }^{1}$ Department of Large Animal Clinical Sciences, University of Tennessee College of Veterinary Medicine, 2407 River Drive, \\ Knoxville, TN 37996, USA \\ ${ }^{2}$ Department of Biomedical and Diagnostic Sciences, University of Tennessee College of Veterinary Medicine, \\ 2407 River Drive, Knoxville, TN 37996, USA \\ Correspondence should be addressed to Claudia Cruz Villagrán; ccruz@utk.edu
}

Received 4 March 2014; Revised 27 May 2014; Accepted 28 May 2014; Published 12 June 2014

Academic Editor: Lysimachos G. Papazoglou

Copyright (C) 2014 Claudia Cruz Villagrán et al. This is an open access article distributed under the Creative Commons Attribution License, which permits unrestricted use, distribution, and reproduction in any medium, provided the original work is properly cited.

A 27-year-old, American Quarter Horse gelding was evaluated for anorexia, lethargy, a swelling on the right, cranial aspect of the neck, and signs of esophageal obstruction. Serum biochemical analyses revealed hypophosphatemia, total and ionized hypercalcemia, and hemoconcentration. Sonographic examination of the neck revealed a $1.7 \mathrm{~cm}$ diameter mass within the right lobe of the thyroid. The serum concentration of intact parathyroid hormone (iPTH) was increased. The right lobe of the thyroid was excised with the horse sedated. The mass within that lobe was determined, by histological examination, to be a parathyroid adenoma. Despite excision of the mass, serial blood analyses revealed persistent hypercalcemia, hypophosphatemia, and increased iPTH. Anorexia and lethargy resolved, and follow-up communication with the owner and referring veterinarian one year later indicated that the horse was clinically stable.

\section{Case Presentation}

A 27-year-old, $500 \mathrm{~kg}$, American Quarter Horse gelding, kept as a pet, was presented to the University of Tennessee Veterinary Medical Center with signs of esophageal obstruction for 12 hours, including hypersalivation, frequent stretching of the neck, and signs of discomfort. The horse, along with other pasture mates, had been treated for cantharidin toxicity 2 years previously. It was housed in a stall and had free access to pasture. Its diet consisted of orchard grass hay provided ad libitum, $800 \mathrm{~g}$ oats, and $300 \mathrm{~g}$ complete pelleted feed containing $0.8 \%$ calcium ( $\%$ of dry matter), $0.4 \%$ phosphorus, and $14 \%$ crude protein, fed twice daily. The horse had been vaccinated and dewormed regularly by the referring veterinarian.

When presented, the horse was dull, tachycardic (80 bpm), and dehydrated (6\% on the basis of tacky mucosal membranes). Respiratory rate and temperature were normal. The packed cell volume was $0.48 \mathrm{~L} / \mathrm{L}$ (reference interval, $0.28-0.44 \mathrm{~L} / \mathrm{L}$ ), and total solids were $8.2 \mathrm{~g} / \mathrm{dL}$ (range, 6$8 \mathrm{~g} / \mathrm{dL}$ ) when measured with a refractometer. The horse's body condition score was 4/9 [1]. No cardiac arrhythmias, murmurs, or abnormal lung sounds were auscultated. No abnormalities were detected during palpation of abdominal viscera performed per rectum, and a nasogastric tube was inserted into the stomach without resistance. The absence of two maxillary cheek teeth and the presence of malocclusion and mild enamel points were observed during examination of the horse's oral cavity, but no evidence of severe periodontal disease was found. Palpation of the neck revealed a firm, mobile, subcutaneous mass in the right, cranial aspect of the neck, thought to be the right lobe of the thyroid gland.

The primary problems identified included lethargy, tachycardia, dehydration, poor dentition, and a mass on the neck. Causes of lethargy considered were inflammation, electrolyte imbalance, and neurologic, renal, GI, respiratory, and endocrine disease. The lethargy and anorexia were most likely related to the underlying disease. Causes of tachycardia considered were pain, stress, endotoxemia, electrolyte and metabolic imbalances, hypovolemia, anemia, endotoxemia, and cardiopathy. Causes of dehydration considered were profuse sweating, decreased water intake, renal failure, hemorrhage, and GI disease. Although esophageal obstruction was the presenting complaint, this problem had resolved before or 


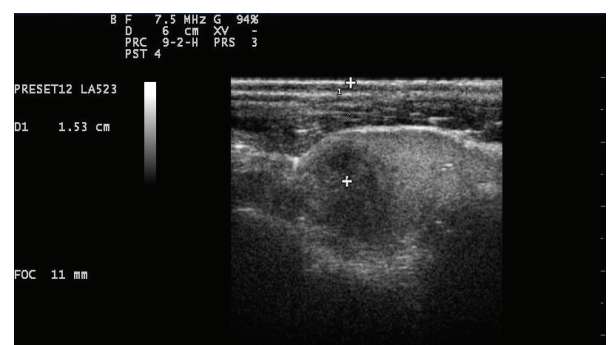

Figure 1: Transverse ultrasonographic image of the right lobe of the thyroid gland showing a $1.7 \mathrm{~cm}$ diameter, hypoechoic, circular mass within the thyroid gland. Image obtained with a $7.5 \mathrm{MHz}$, linear probe.

soon after arrival and was attributed to poor dentition. At this point, further diagnostic tests were conducted to determine the cause of the identified problems.

Abnormalities on CBC and plasma biochemical analyses included a mature $\left(10.92 \times 10^{3} / \mu \mathrm{L}\right.$; reference interval, $\left.2.6-5.5 \times 10^{3} / \mu \mathrm{L}\right)$ and immature $\left(0.94 \times 10^{3} / \mu \mathrm{L} ; 0-\right.$ $\left.0.1 \times 10^{3} / \mu \mathrm{L}\right)$ neutrophilia without toxic changes, slightly increased plasma concentration of creatinine $(2.1 \mathrm{mg} / \mathrm{dL} ; 0.9-$ $1.7 \mathrm{mg} / \mathrm{dL})$, hypophosphatemia $(1.0 \mathrm{mg} / \mathrm{dL} ; 1.9-4.1 \mathrm{mg} / \mathrm{dL})$, total hypercalcemia $(18.4 \mathrm{mg} / \mathrm{dL} ; 11.3-13.2 \mathrm{mg} / \mathrm{dL})$, and ionized hypercalcemia $(10.5 \mathrm{mg} / \mathrm{dL} ; 5-7 \mathrm{mg} / \mathrm{dL})$. Results of a urine dipstick test on a free-catch urine sample were normal. The horse was administered polyionic fluid therapy intravenously by continuous rate infusion at $60 \mathrm{~mL} / \mathrm{kg} /$ day for 2 days after first administering a 10-L bolus.

On day 2, urine obtained through a urinary catheter inserted aseptically into the bladder had a specific gravity of 1.025. Fluid therapy was discontinued at the end of day 2 because the horse was euhydrated (PCV, 0.36 L/L; TS, $7 \mathrm{~g} / \mathrm{dL}$ ) and because the horse's urine had a normal specific gravity. Results of urinalysis were normal. Ultrasonographic examination of the mass on the neck revealed a $1.7 \mathrm{~cm}$ diameter, hypoechoic, circular mass of homogeneous density contained within the right lobe of the thyroid gland (Figure 1). The left lobe of the thyroid gland had a normal appearance. No ultrasonographic abnormalities were observed during thoracic, transabdominal, and transrectal examinations. The left kidney appeared to be normal in size when it was palpated per rectum, and both kidneys appeared to be normal in size, based on their ultrasonographic appearance. An attempt to obtain an ultrasound-guided, fine-needle aspirate of the mass contained within the right lobe of the thyroid gland was unsuccessful. During radiographic examination of the skull, the density of the dental alveoli appeared to be normal, and no signs of apical dental infection were observed. No abnormalities were observed during radiographic examination of the thorax. Administration of omeprazole $(1 \mathrm{mg} / \mathrm{kg}, \mathrm{PO}$, q24 h) was initiated after mild hyperemia of the nonglandular mucosa of the stomach was observed during gastroscopy. Ionized serum calcium, measured daily, remained increased. The serum concentration of iPTH $(14.1 \mathrm{pmol} / \mathrm{L}$; reference < $4 \mathrm{pmol} / \mathrm{L}$ [2]. Diagnostic Center for Population and Animal Health laboratory, Michigan State University) was increased, and the serum concentration of 1,25-di-hydroxyvitamin
$\mathrm{D}_{3}$ was within normal range $(17 \mathrm{nmol} / \mathrm{L} ; 10-25 \mathrm{nmol} / \mathrm{L})$. Parathyroid hormone-related protein (PTHrP) could not be measured because the immunoassay reagent was not available at the time.

On day 3, calculation of fractional clearance of electrolytes in the urine revealed low fractional clearance of calcium $(0.55 \% ; 5.3-14.5 \%)$, which was attributed to increased reabsorption of calcium from the renal tubules in response to increased serum concentration of PTH. Fractional clearance of sodium $(0.36 \%$; reference $<1 \%)$ and phosphorous $(0.9 \%$; reference $<1 \%)$ was normal [3]. Serum urea nitrogen $(12 \mathrm{mg} / \mathrm{dL})$ and creatinine $(1.9 \mathrm{mg} / \mathrm{dL})$ concentrations had decreased, suggesting that the azotemia present when the horse was presented was prerenal. Although these analyses did not support a diagnosis of glomerular or tubular renal failure, a certain degree of renal insufficiency was still considered to be a possible cause of the horse's anorexia given its previous exposure to cantharidin. Administration of trimethoprim-sulfamethoxazole $(20 \mathrm{mg} / \mathrm{kg}$ PO q12 h) was initiated, after the horse received extensive dental work because of concerns that this dental work may have caused bacteria to shed into the circulation and also because of concerns that the horse may have aspirated feed during the episode of choke.

The horse was determined to be suffering from primary hyperparathyroidism on the basis of the increased serum iPTH concentration, hypercalcemia, hypophosphatemia, low fractional clearance of calcium, clinical signs, and ultrasonographic findings. Lethargy persisted, but appetite and water consumption improved. The horse was discharged on day 4 , and the owner was instructed to continue administering omeprazole $(1 \mathrm{mg} / \mathrm{kg}, \mathrm{PO} \mathrm{q} 24 \mathrm{~h})$ for 4 days and trimethoprim-sulfamethoxazole $(20 \mathrm{mg} / \mathrm{kg}, \mathrm{PO}, \mathrm{q} 12 \mathrm{~h})$ for 5 days.

Ten days after discharge, the horse was readmitted to undergo excision of the right lobe of the thyroid gland and the suspected parathyroid adenoma contained within it. The horse had a lower body condition score (3/9) and appeared dull. Results of serum biochemical analyses revealed total $(17 \mathrm{mg} / \mathrm{dL} ; 11.3-13.2 \mathrm{mg} / \mathrm{dL})$ and ionized hypercalcemia $(9.64 \mathrm{mg} / \mathrm{dL} ; 5-7 \mathrm{mg} / \mathrm{dL})$, hypophosphatemia $(1.7 \mathrm{mg} / \mathrm{dL} ; 1.9-4.1 \mathrm{mg} / \mathrm{dL})$, and a mild hypertriglyceridemia (88 mg/dL; $10-77 \mathrm{mg} / \mathrm{dL})$ consistent with a negative energy balance and release of lipids into the circulation. Results of PCV $(0.48 \mathrm{~L} / \mathrm{L})$ and TS $(7 \mathrm{~g} / \mathrm{dL})$ indicated that the horse was euhydrated. Serum urea nitrogen $(15 \mathrm{mg} / \mathrm{dL})$ and creatinine $(2 \mathrm{mg} / \mathrm{dL})$ remained stable.

To remove the right lobe of the thyroid with the horse standing, the horse was sedated with detomidine hydrochloride $(0.02 \mathrm{mg} / \mathrm{kg}, \mathrm{IV})$ and butorphanol tartrate $(0.01 \mathrm{mg} / \mathrm{kg}$, IV). The right cranial portion of the neck was prepared for aseptic surgery, and the proposed site of incision over the palpable right lobe of the thyroid was desensitized by subcutaneous injection of $2 \%$ mepivacaine hydrochloride. A $5 \mathrm{~cm}$, longitudinal, cutaneous incision was created over the right lobe of the thyroid gland, which was exposed by sharply dividing the overlying cutaneous colli muscle. Traction was placed on the gland with a suture of 0 polypropylene inserted through the gland. The lobe was separated from surrounding 


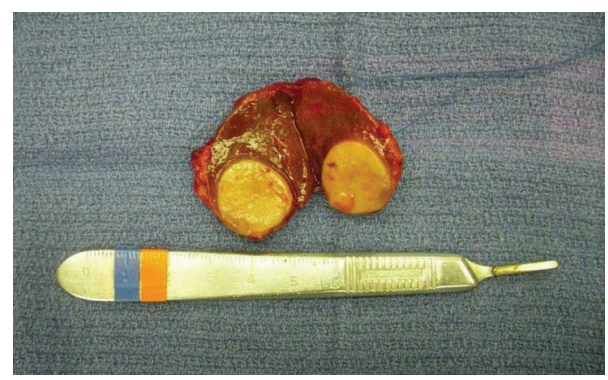

Figure 2: Right thyroid lobe excised from the horse. Note the circular parathyroid adenoma.

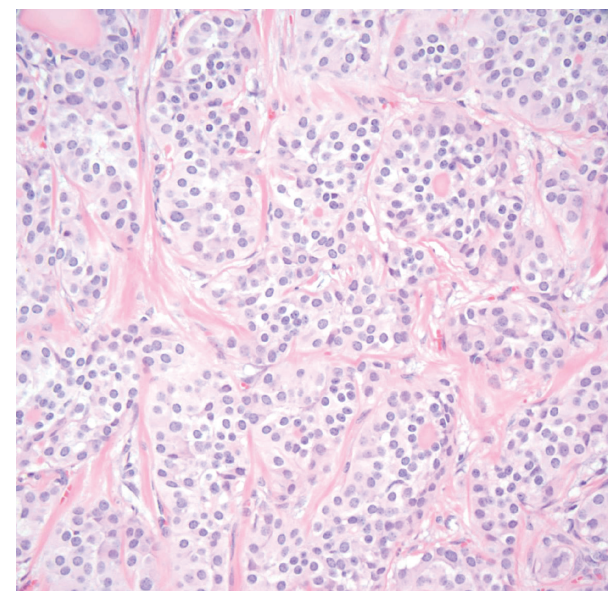

FIGURE 3: Histologic section of neoplasm within the right thyroid lobe excised from the horse. Hematoxylin and eosin, 20x.

fascia and removed after the thyroid artery and vein at the cranial aspect of the gland were ligated with 2-0 polydioxanone sutures and divided. The cutaneous colli muscle and subcutaneous tissue were apposed separately with $2-0$ polydioxanone suture placed in a simple-continuous pattern, and the cutaneous incision was closed with staples. The horse was administered firocoxib $(0.27 \mathrm{mg} / \mathrm{kg}$, IV, loading dose; $0.09 \mathrm{mg} / \mathrm{kg}$, IV, q24 h for subsequent doses) for 3 days. Staples were removed 12 days after surgery.

Gross examination of the right lobe of the thyroid gland revealed a circular, well-delineated, $1.7 \mathrm{~cm}$ diameter, white mass (Figure 2). Polygonal to cuboidal cells arranged in packets with fine, fibrovascular stroma and low mitotic activity were observed during histologic examination of the mass (Figure 3). The nuclei of these cells had stippled chromatin with moderate amounts of pale, foamy to granular cytoplasm. The immunohistochemical antibody for PTH was ineffective on the parathyroid gland tissue from this horse, but the neoplastic cells stained strongly for chromogranin A (Figure 4) and did not stain for calcitonin or thyroglobulin. These findings confirmed the presence of a neuroendocrine tumor, most likely a parathyroid adenoma based on the clinical signs and high concentrations of iPTH and ionized calcium. The tissue surrounding the mass was compressed thyroid tissue.

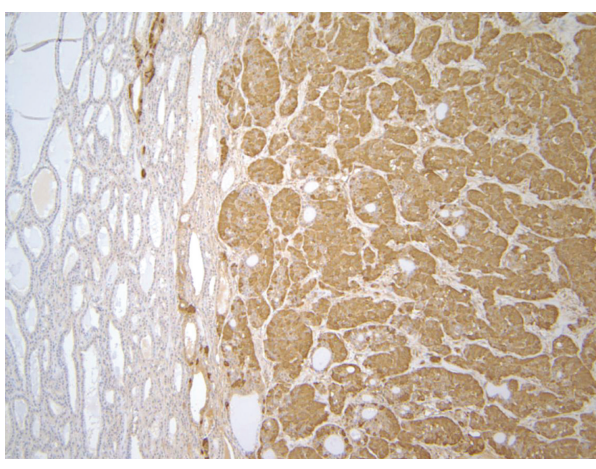

Figure 4: Chromogranin A immunostain on parathyroid tissue. There is diffuse strong cytoplasmic staining of the neoplastic cells. Adjacent thyroid follicles are negative for immunostaining of chromogranin A.

Ten days after partial thyroidectomy, the serum concentrations of iPTH $(10.3 \mathrm{pmol} / \mathrm{L}$; reference $<4 \mathrm{pmol} / \mathrm{L})$ and ionized calcium $(9.64 \mathrm{mg} / \mathrm{dL} ; 5-7 \mathrm{mg} / \mathrm{dL})$ remained increased. The horse's clinical appearance and demeanor were normal, and its appetite gradually increased. The horse was discharged 19 days after surgery. The owner was instructed to observe the horse for signs of synchronous diaphragmatic flutter in case the horse's serum concentration of calcium decreased leading to this complication. Bags containing $50 \mathrm{~g}$ of calcium carbonate powder (limestone) were provided to the owner to administer orally to the horse if this complication developed.

When the horse was examined 30 days after discharge, its serum concentrations of iPTH $(23.9 \mathrm{pmol} / \mathrm{L}$; reference $<4 \mathrm{pmol} / \mathrm{L})$ and ionized calcium $(8.28 \mathrm{mg} / \mathrm{dL} ; 5-7 \mathrm{mg} / \mathrm{dL})$ remained increased, suggesting the presence of other neoplastic or hyperplastic parathyroid glands or MEN-like syndrome [4]. At 60 days after discharge, serum concentrations of thyroid hormones, total $\mathrm{T}_{3}$ and $\mathrm{T}_{4}$, were decreased from concentrations considered to be normal $\left(\mathrm{T}_{3}, 0.18 \mathrm{ng} / \mathrm{L}\right.$; reference, $0.5-1.5 \mathrm{ng} / \mathrm{L}$ and $\mathrm{T}_{4},<1.7 \mathrm{ng} / \mathrm{L} ; 3.65-26 \mathrm{ng} / \mathrm{L}$ ), and ionized hypercalcemia was still present $(9.8 \mathrm{mg} / \mathrm{dL} ; 5-7 \mathrm{mg} / \mathrm{dL})$. Serum urea nitrogen $(16 \mathrm{mg} / \mathrm{dL})$ and creatinine $(2.1 \mathrm{mg} / \mathrm{dL})$ had remained stable. After cautioning the owner about the danger of inducing hypovolemia, renal failure, and shock by administering furosemide to a dehydrated horse, the owner was instructed to administer furosemide for 14 days $(0.5 \mathrm{mg} / \mathrm{kg}, \mathrm{PO} \mathrm{q} 12 \mathrm{~h})$ to promote diuresis and calciuresis and to supplement the horse's diet with levothyroxine sodium (24 mg total, PO, q24h; Thyro-L, Vet-A-Mix, Inc., Shenandoah, IA) indefinitely.

The owner indicated during a telephone conversation, conducted one year after the presumed parathyroid adenoma and right lobe of the thyroid gland were removed, that the horse's appetite and attitude were normal. Intact PTH and concentrations of electrolytes in the serum were not measured.

\section{Discussion}

Primary hyperparathyroidism is a rare disease of the horse caused by parathyroid neoplasia or hyperplasia $[5,6]$. Other 
causes of increased concentration of iPTH include nutritional and renal secondary hyperparathyroidism and production of PTHrP from MEN [2, 6-8]. PTH is closely involved in calcium homeostasis, and its secretion from the chief cells of the parathyroid glands is regulated by a negative feedback mechanism that involves serum concentrations of calcium, PTH, and 1,25-di-hydroxyvitamin D [2]. Serum concentrations of magnesium and PTH are also codependent but in a more complex manner [9]. The effects of PTH on various target cells include enhanced reabsorption of calcium by the renal tubules, increased absorption of calcium from the small intestine, decreased reabsorption and increased excretion of phosphorous from the renal tubules, increased excretion of phosphorus from the salivary glands, and increased synthesis of 1,25 -di-hydroxyvitamin $\mathrm{D}$ by the kidney $[2,6]$. The equine parathyroid glands, usually 1 or sometimes 2 on each side of the neck, are located adjacent to or within each lobe of the thyroid gland, but their number and location vary among horses $[10,11]$. In humans, single or multiple adenomas can arise in each parathyroid gland, and multiple parathyroid glands can be affected [12].

Differential diagnoses for hypercalcemia in the horse include chronic renal failure, hypervitaminosis $\mathrm{D}$, nutritional secondary hyperparathyroidism (including consumption of oxalates in forage), primary hyperparathyroidism, hypercalcemia of malignancy, and multiple endocrine neoplasia(MEN-) like syndrome $[4-6,13,14]$. The clinical history and laboratory and ultrasonographic findings made hypervitaminosis D, chronic renal failure, and nutritional secondary hyperparathyroidism less likely to be the cause of this horse's hypercalcemia.

Malignant neoplasms secrete an exaggerated amount of PTHrP, which can imitate several functions of PTH due to molecular similarities between these 2 peptides (i.e., 6 of the first 7 amino acids are identical between them) [15]. Dogs and cats suffering from hypercalcemia of malignancy have a high serum concentration of PTHrP, but their serum concentration of $\mathrm{iPTH}$ is normal or low, unless the malignancy is a functional parathyroid adenocarcinoma [8]. Despite our inability to rule out hypercalcemia due to malignancy elsewhere in this horse, the persistently high iPTH and the improvement on clinical signs even after a year later do not support a diagnosis of hypercalcemia caused by malignancy. Primary hyperparathyroidism and MEN-like syndrome remained as likely causes for the hypercalcemia.

Chronic renal failure was initially considered as a cause of hypercalcemia in this case because the horse had been exposed to cantharidin 2 years previously. Cantharidin irritates the gastrointestinal and urinary tracts directly and can result in colic, renal failure, shock, and death [16]. Fractional excretion of sodium, an indicator of renal tubular function, was found to be normal. Other tests of renal function were not performed, but serum urea nitrogen and creatinine concentrations decreased in response to fluid therapy and remained constant after its discontinuation.

Clinical signs of hyperparathyroidism in horses include lethargy, generalized weakness, lameness, and enlarged facial bones [5, 17-19]. Weakness is attributed to increased extracellular calcium because calcium concentration plays a role in the onset of action potentials, primarily in neurons and smooth and cardiac myocytes. Hypercalcemia raises the resting membrane potential causing, in humans, clinical manifestations of depression of the central and peripheral nervous system, anorexia, muscular weakness, and constipation $[20,21]$.

The horse in this report was determined to have hypercalcemia and hyperparathyroidism 30 days after surgery. The horse remained anorexic and dull for several days after surgery, and this was attributed to persistent hypercalcemia $[17,19]$. We can find no reports describing the amount of time required for calcium concentrations to return to normal in horses after a functional parathyroid adenoma is removed. Humans that have had one or more parathyroid glands removed are expected to experience a decrease in the concentration of serum calcium after 4 days, and dogs undergoing a similar procedure are expected to show a similar decrease after 7 days $[22,23]$. Persistent hypercalcemia can also occur after one or more parathyroid glands of dogs are removed, and when this occurs, the presence of ectopic, active parathyroid tissue, hyperplasia of parathyroid tissue, or an adenoma of one or more of the remaining parathyroid glands is suspected $[8,22]$.

Radiographic assessment of the skull revealed no resorption of facial or alveolar bone, a predominant sign of osteodystrophia fibrosa, which can result from hyperparathyroidism. The long bones of this horse were not radiographed to detect osteopenia because of economic reasons. Although osteopenia caused by hyperparathyroidism preferentially affects facial bones, other bones could have been affected. The clinician should also be aware of the timing between detection of hyperparathyroidism and radiological assessment.

The diagnosis of primary hyperparathyroidism in this horse was based on clinical signs, the presence of elevated serum concentrations of iPTH and total and ionized calcium, hypophosphatemia, and low fractional excretion of calcium. Hypophosphatemia with hyperphosphaturia is typical of primary hyperparathyroidism. PTH prevents the reabsorption of phosphorus from the brush border membrane of the proximal tubule by inhibiting the sodium-phosphate cotransporter, resulting in enhanced renal phosphorus excretion [24]. With a low phosphorus intake, however, the body is able to maximize phosphorus conservation by being resistant to the action of PTH in the kidney [25]. Renal phosphorus excretion in this horse was normal. Our most logical explanation for the hypophosphatemia is that the horse had decreased intake of phosphorus due to prolonged anorexia, but phosphorus was maximally conserved in the face of hyperparathyroidism by mechanisms that enhanced renal reabsorption of phosphorus, attenuating the phosphaturic action of PTH. Hyperphosphaturia would possibly have been detected if the horse had had a normal appetite at the time that fractional excretion of electrolytes was examined.

Histological and immunohistochemical analyses of the tissue excised from the horse contrasted. The absence of staining for calcitonin and thyroglobulin ruled out thyroid neoplasia. The presence of strong, diffuse staining for chromogranin A indicated that the mass was of neuroendocrine origin, suggesting parathyroid origin, based on clinical signs 
and an increased concentration of iPTH [26]. We could not confirm this, however, because the monoclonal rat antihuman PTH antibody did not stain the mass. Possibilities for lack of staining may include species-specific issues and the fact that the tumour was originated from tissue other than a parathyroid gland.

Treatment of horses for primary hyperparathyroidism requires excision of the neoplastic parathyroid gland. Excision is sometimes challenging because the location and number of parathyroid glands vary among horses, making locating and removing the affected gland or glands difficult [5, $18,19]$. Preoperative scintigraphy may help locate parathyroid tissue [27]. In a retrospective study of dogs suffering from hyperparathyroidism, parathyroidectomy of the affected glands, ultrasound-guided, percutaneous, radiofrequencyinduced heat ablation, or chemical ablation using ethanol resulted in a 94,90 , and $72 \%$ success rate, respectively, in resolving hypercalcemia $[22,28]$.

Calcimimetic drugs, which act as activators of the calcium-sensing receptors in the parathyroid gland and other tissues, thereby reducing the release of $\mathrm{PTH}$, are used to treat humans for hyperparathyroidism secondary to chronic kidney disease [17, 23]. Additionally, bisphosphonates are administered to prevent bone resorption and to lower the serum concentration of calcium [23]. We can find no reports describing the use of calcimimetic or bisphosphonate drugs to treat horses for hyperparathyroidism, but treatment with these drugs might prevent bone resorption caused by it. Regardless, because the horse in this report had no signs of excessive resorption of the bone, we administered neither of these medications.

Levothyroxine sodium was administered after the concentrations of serum thyroid hormones were found to be low 60 days after the right lobe of the thyroid gland was excised. Levothyroxine sodium has been administered to humans suffering from hypothyroidism because it returns the concentrations of thyroid hormones to normal. Administering levothyroxine sodium to healthy horses for 48 weeks increased the total concentration of $\mathrm{T}_{4}$ without causing adverse effects on health [29]. No changes to the diet of this horse were recommended because the phosphorous-calcium ratio of the diet was appropriate.

Removing the presumed parathyroid adenoma within the right lobe of the thyroid gland failed to resolve the hypercalcemia in this horse, and iPTH concentrations were still increased when a follow-up examination was performed one month after surgery. We suspected, therefore, that multiple parathyroid adenomas were present in this horse. MENlike syndrome was also possible. The absence of clinical signs associated with hyperparathyroidism one month after surgery was also difficult to explain. Absence of clinical signs associated with hyperparathyroidism after excision of neoplastic parathyroid tissue has been reported previously in a mule [19] and in humans [23]. We assumed the horse had absence of clinical signs of disease because it had adapted to the hypercalcemia or because it had responded to the treatments administered at our hospital. Humans can develop high serum concentrations of calcium associated with asymptomatic primary hyperparathyroidism, and excision of the affected gland is delayed until the concentration of calcium becomes so high that it results in symptoms by exerting negative effects on neurological, renal, and musculoskeletal functions [23].

This report describes the clinical signs and diagnosis of primary hyperparathyroidism, detection of a neuroendocrine tumour of unknown origin within the thyroid gland, and surgical management of the horse. A unique aspect of this case is the resolution of clinical signs associated with hyperparathyroidism after surgery, despite the persistence of increased concentrations of serum iPTH and iCa. Presence of a second parathyroid adenoma or MEN-like syndrome was highly suspected. Additional diagnostic and treatment options were declined by the owner because clinical signs of hyperparathyroidism resolved.

\section{Conflict of Interests}

The authors declare that there is no conflict of interests regarding the publication of this paper.

\section{References}

[1] D. R. Henneke, G. D. Potter, J. L. Kreider, and B. F. Yeates, "Relationship between condition score, physical measurements and body fat percentage in mares," Equine veterinary journal, vol. 15, no. 4, pp. 371-372, 1983.

[2] R. E. Toribio, "Disorders of the endocrine system," in Equine Internal Medicine, S. M. Reed, W. M. Bayly, and D. Sellon, Eds., pp. 1248-1311, WB Saunders, Philadelphia, Pa, USA, 3rd edition, 2009.

[3] J. E. Cunilleras, "Abnormalities of body fluids and electrolytes in equine athletes," in Equine Sports Medicine and Surgery, vol. 914, Saunders, Philadelphia, Pa, USA, 2004.

[4] S. E. Germann, M. Rütten, S. B. Derungs, and K. Feige, "Multiple endocrine neoplasia-like syndrome in a horse," Veterinary Record, vol. 159, no. 16, pp. 530-532, 2006.

[5] N. Frank, J. F. Hawkins, L. L. Couëtil, and J. T. Raymond, "Primary hyperparathyroidism with osteodystrophia fibrosa of the facial bones in a pony," Journal of the American Veterinary Medical Association, vol. 212, no. 1, pp. 84-86, 1998.

[6] J. R. Peauroi, D. J. Fisher, F. C. Mohr, and S. L. Vivrette, "Primary hyperparathyroidism caused by a functional parathyroid adenoma in a horse," Journal of the American Veterinary Medical Association, vol. 212, no. 12, pp. 1915-1918, 1998.

[7] N. A. Benders, K. Junker, T. Wensing, T. S. G. A. M. van den Ingh, and J. H. van der Kolk, "Diagnosis of secondary hyperparathyroidism in a pony using intact parathyroid hormone radioimmunoassay," Veterinary Record, vol. 149, no. 6, pp. 185$187,2001$.

[8] P. J. Bergman, "Paraneoplastic hypercalcemia," Topics in Companion Animal Medicine, vol. 27, no. 4, pp. 156-158, 2012.

[9] T. Vetter and M. J. Lohse, "Magnesium and the parathyroid," Current Opinion in Nephrology and Hypertension, vol. 11, no. 4, pp. 403-410, 2002.

[10] L. Krook and J. E. Lowe, "Nutritional secondary hyperparathyroidism in the horse, with a description of the normal anatomy of the normal equine parathyroid gland," Veterinary Pathology, supplement 1, pp. 1-98, 1964. 
[11] International Committee on Veterinary Gross Anatomy Nomenclature, "Glandulae endocrinae," in Nomina Anatomica Veterinaria, pp. 64-65, Editorial Committee, 5th edition, 2012.

[12] N. W. Thompson, F. E. Eckhauser, and J. K. Harness, "The anatomy of primary hyperparathyroidism," Surgery, vol. 92, no. 5, pp. 814-821, 1982.

[13] M. H. Barton, P. Sharma, B. E. LeRoy, and E. W. Howerth, "Hypercalcomia hypercalcemia and high serum parathyroid hormone-related protein concentration in a horse with multiple myeloma," Journal of the American Veterinary Medical Association, vol. 225, no. 3, pp. 409-376, 2004.

[14] R. E. Toribio, C. W. Kohn, K. M. Rourke, A. L. Levine, and T. J. Rosol, "Effects of hypercalcemia on serum concentrations of magnesium, potassium, and phosphate and urinary excretion of electrolytes in horses," The American Journal of Veterinary Research, vol. 68, no. 5, pp. 543-554, 2007.

[15] K.-D. Schlüter, "PTH and PTHrP: similar structures but different functions," News in Physiological Sciences, vol. 14, no. 6, pp. 243-248, 1999.

[16] R. G. Helman and W. C. Edwards, "Clinical features of blister beetle poisoning in equids: 70 cases (1983-1996)," Journal of the American Veterinary Medical Association, vol. 211, no. 8, pp. 1018-1021, 1997.

[17] A. A. Khan, "Medical management of primary hyperparathyroidism," Journal of Clinical Densitometry, vol. 16, no. 1, pp. 6063, 2013.

[18] J. R. Joyce, K. R. Pierce, W. M. Romane, and J. M. Baker, "Clinical study of nutritional secondary hyperparathyroidism in horses," Journal of the American Veterinary Medical Association, vol. 158, no. 12, pp. 2033-2042, 1971.

[19] D. Wong, B. Sponseller, K. Miles, T. Butt, and K. Kersh, "Failure of technetium Tc $99 \mathrm{~m}$ sestamibi scanning to detect abnormal parathyroid tissue in a horse and a mule with primary hyperparathyroidism," Journal of Veterinary Internal Medicine, vol. 18, pp. 589-593, 2004.

[20] E. M. Brown and R. J. Macleod, "Extracellular calcium sensing and extracellular calcium signaling," Physiological Reviews, vol. 81, no. 1, pp. 239-297, 2001.

[21] J. E. Hall, "Parathyroid hormone, calcitonin, calcium and phosphate metabolism, vitamin D, bone and teeth," in Guyton and Hall Textbook of Medical Physiology, J. E. Hall, Ed., pp. 955-972, WB Saunders, Philadelphia, Pa, USA, 12th edition, 2011.

[22] R. W. Nelson, "Disorders of the parathyroid gland," in Small Animal Internal Medicine, R. W. Nelson and G. C. Couto, Eds., pp. 715-723, Mosby-Elsevier, 4th edition, 2009.

[23] J. E. Witteveen, S. van Thiel, J. A. Romijn, and N. A. Hamdy, "Hungry bone syndrome: still a challenge in the post-operative management of primary hyperparathyroidism: a systematic review of the literature," European Journal of Endocrinology, vol. 168, no. 3, pp. R45-53, 2013.

[24] H. Murer, A. Werner, S. Reshkin, F. Wuarin, and J. Biber, "Cellular mechanisms in proximal tubular reabsorption of inorganic phosphate," The American Journal of Physiology-Cell Physiology, vol. 260, no. 5, pp. C885-C899, 1991.

[25] T. J. Berndt, J. D. Pfeifer, F. G. Knox, S. A. Kempson, and T. P. Dousa, "Nicotinamide restores phosphaturic effect of PTH and calcitonin in phosphate deprivation," The American Journal of Physiology, vol. 242, no. 5, pp. F447-F452, 1982.

[26] L. Luts, A. Bergenfelz, J. Alumets, and F. Sundler, "Parathyroid function and histology in patients with parathyroid adenoma: correlation of clinical and morphologic findings," World Journal of Surgery, vol. 21, no. 5, pp. 553-563, 1997.
[27] J. E. Tomlinson, A. L. Johnson, M. W. Ross et al., "Successful detection and removal of a functional parathyroid adenoma in a pony using Technetium Tc 99m Sestamibi scintigraphy," Journal of Veterinary Internal Medicine, vol. 28, no. 2, 2014.

[28] L. Rasor, R. Pollard, and E. C. Feldman, "Retrospective evaluation of three treatment methods for primary hyperparathyroidism in dogs," Journal of the American Animal Hospital Association, vol. 43, no. 2, pp. 70-77, 2007.

[29] N. Frank, B. R. Buchanan, and S. B. Elliott, "Effects of longterm oral administration of levothyroxine sodium on serum thyroid hormone concentrations, clinicopathologicvariables, and echocardiographic measurements in healthy adult horses," The American Journal of Veterinary Research, vol. 69, no. 1, pp. 68-75, 2008. 

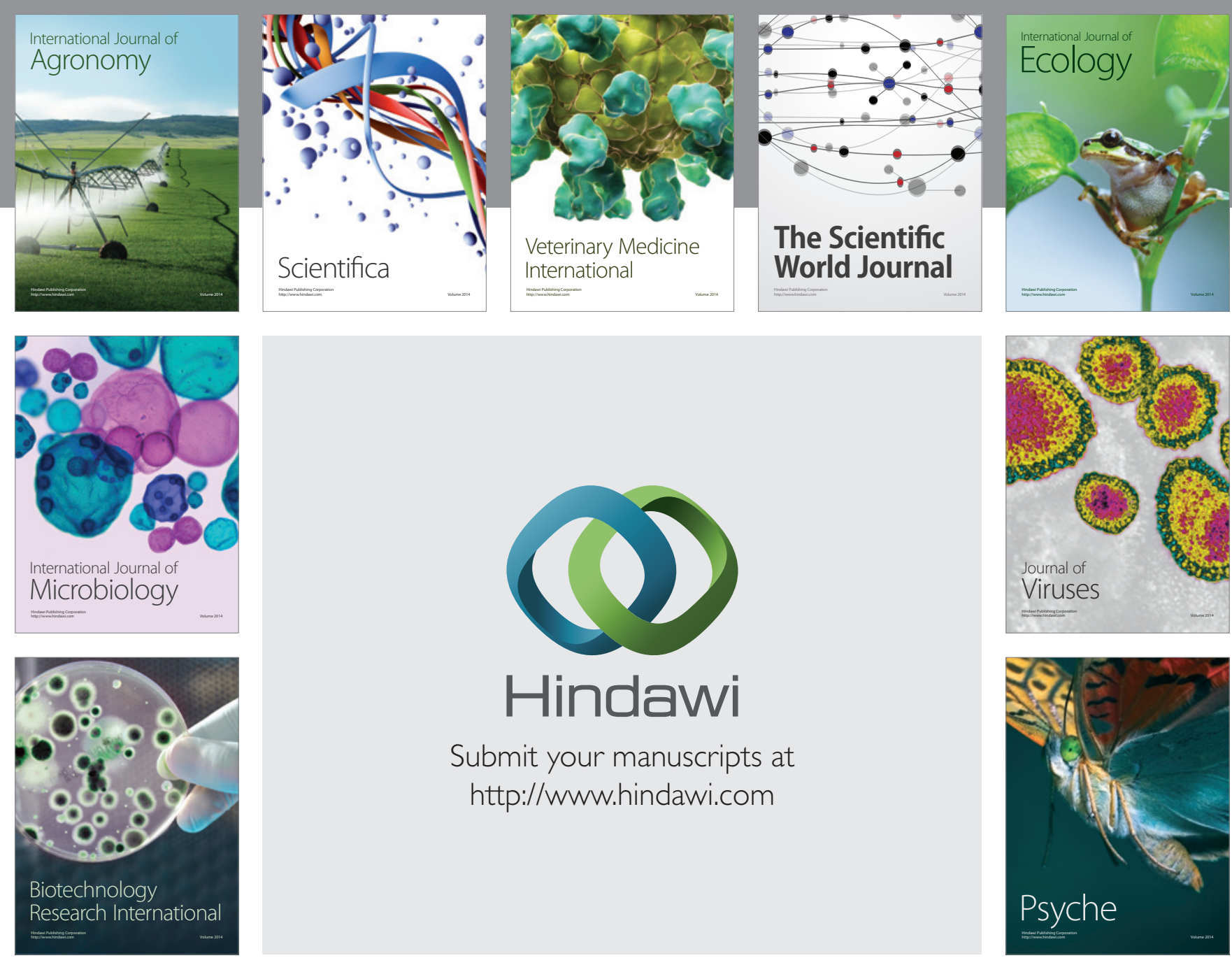

Submit your manuscripts at http://www.hindawi.com
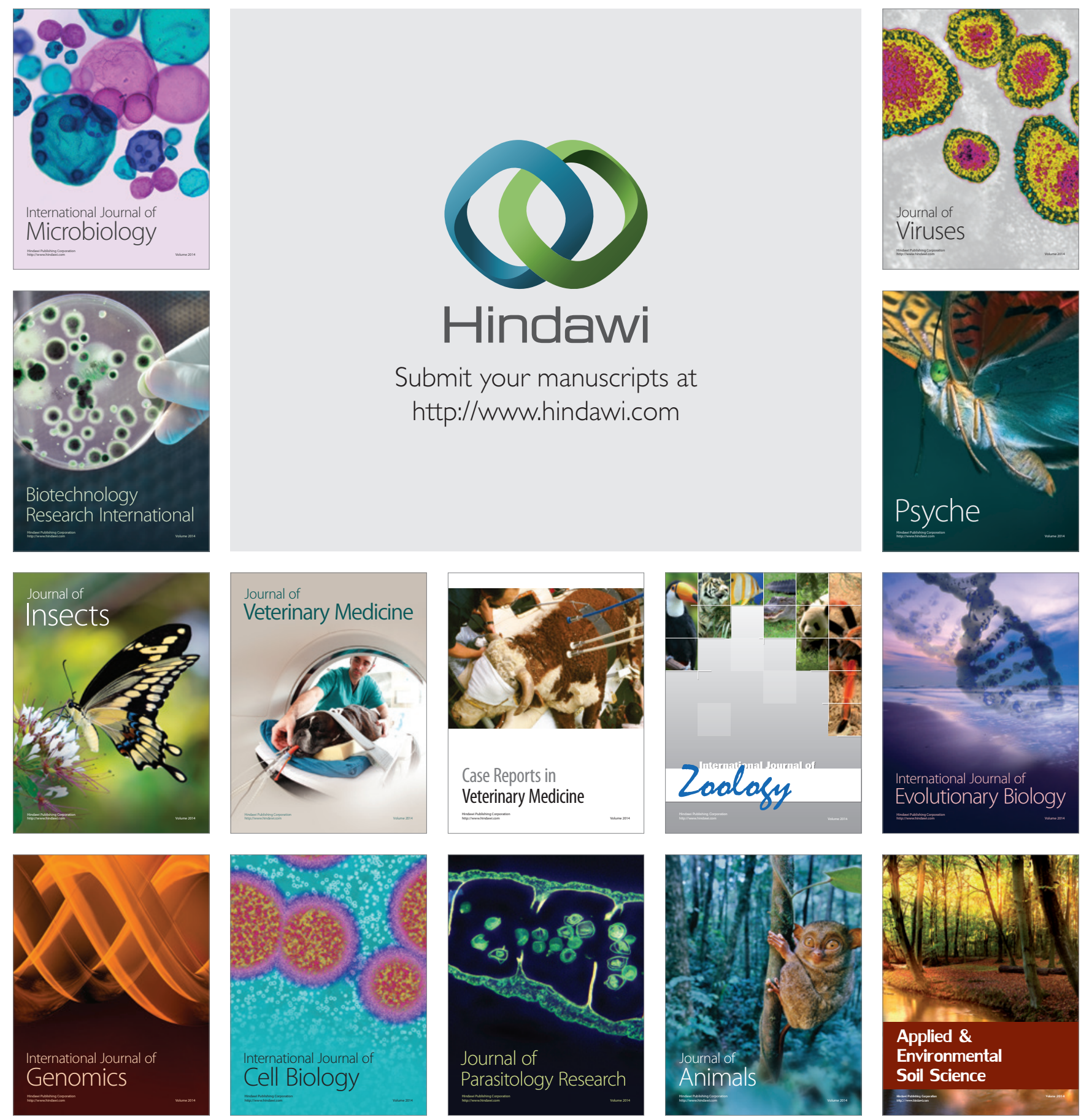